7 ] I R S International Journal of Technical Research \& Science

track the maximum power point voltage using artificial neural network. He also simulated the MPPT in Simulink for operating a solar panel which is supplying load using Buck-Boost Converter. However model is simulated using control blocks. In this paper, I used ANN based MPPT to operate the solar panel so that it can provide constant output voltage across the load using Boost Converter.

\section{OVERVIEW OF SYSTEM}

The proposed system is as below,

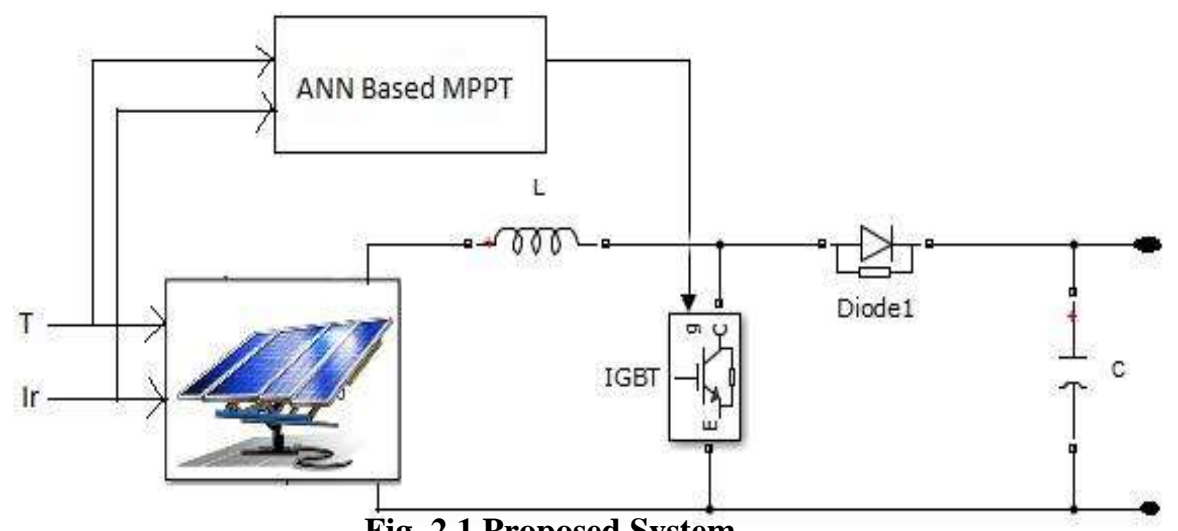

Fig. 2.1 Proposed System

It consists the solar panel, ANN Based MPPT and Boost Converter.

\subsection{Solar Panel}

The model of PV array is taken form MATLAB/Simulink library whose model number is 1Soltech 1STH-215-P.The specification sheet for this panel is as below.

Table-2.1 Specification Sheet for 1STH-215-P

\begin{tabular}{|l|l|}
\hline Parameters & Values \\
\hline Open circuit Voltage & $36.3 \mathrm{~V}$ \\
\hline Short Circuit Current & $7.84 \mathrm{~A}$ \\
\hline Temperature coefficient of Voc & $-0.3699 \% / \mathrm{V}$ \\
\hline Temperature coefficient of Isc & $0.102 \% / \mathrm{A}$ \\
\hline Light Generated current & $7.8649 \mathrm{~A}$ \\
\hline Diode saturation Current & $2.9259 \mathrm{e}-10 \mathrm{~A}$ \\
\hline Diode ideality factor & 0.98117 \\
\hline Shunt Resistance & $313.3991 \mathrm{ohm}$ \\
\hline Series resistance & $0.39383 \mathrm{ohm}$ \\
\hline
\end{tabular}
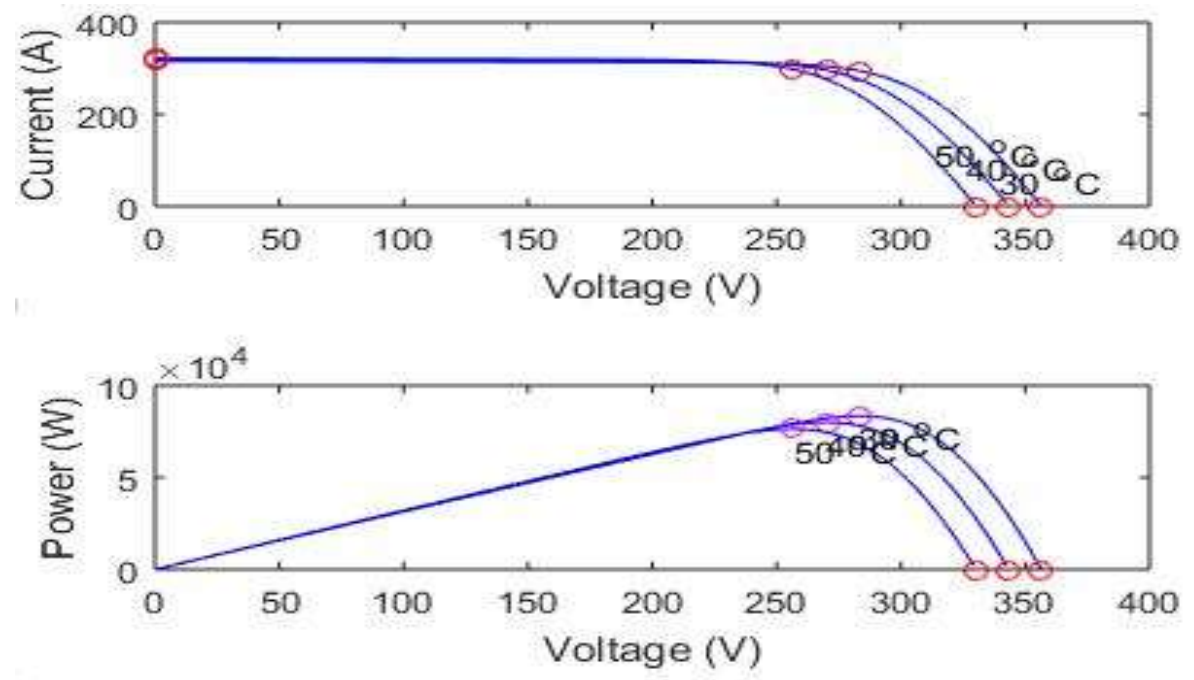

Fig. 2.1 I-V and P-V Curve at Nominal Irradiance $\left(1000 \mathrm{~W} / \mathrm{m}^{2}\right)$

DOI Number: https://doi.org/10.30780/IJTRS.V04.I06.003

pg. 21

www.ijtrs.com

WwW.ijtrs.org

Paper Id: IJTRS-V4-I5-029

Volume IV Issue VI, June 2019 

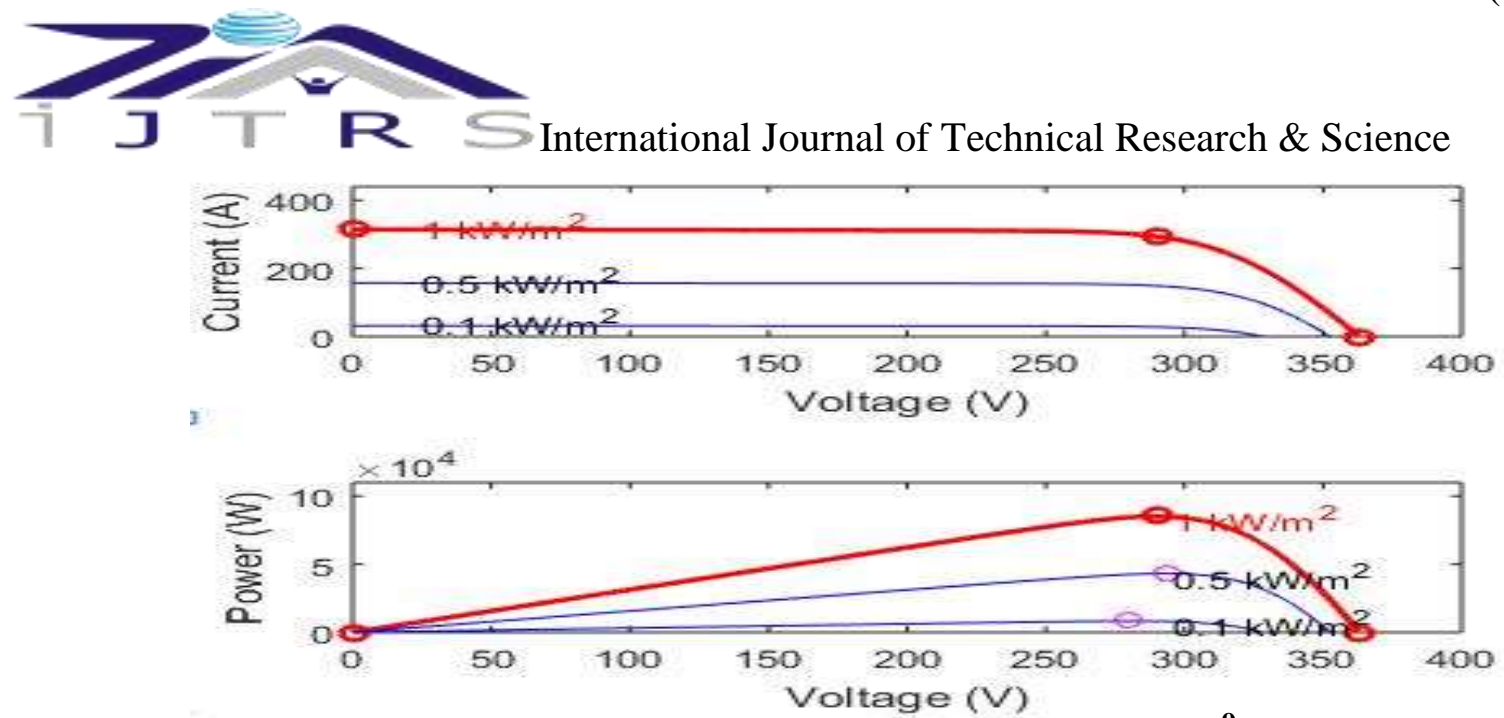

Fig. 2.2 I-V and P-V Curve at Nominal Temperature $\left(25^{\circ} \mathrm{C}\right)$

\subsection{ANN Based MPPT}

Artificial neural networks (ANNs) are the family of statistical learning models inspired by the biological neural networks and they are used to estimate or approximate the functions that can depend on a large number of the inputs and they are generally unknown. Artificial neural networks are the generally presented by the systems of interconnected the "neurons" which send messages to the each other. The connections have numeric weights that can be a tuned based on the experience, making of the neural nets adaptive to the inputs and capable of learning. [4] The ANN model is developed in MATLAB/Simulink environment. A feedforward based neural network with two neurons in input layer, five neurons in output layer and one in output layer is constructed. The model of network is as below.

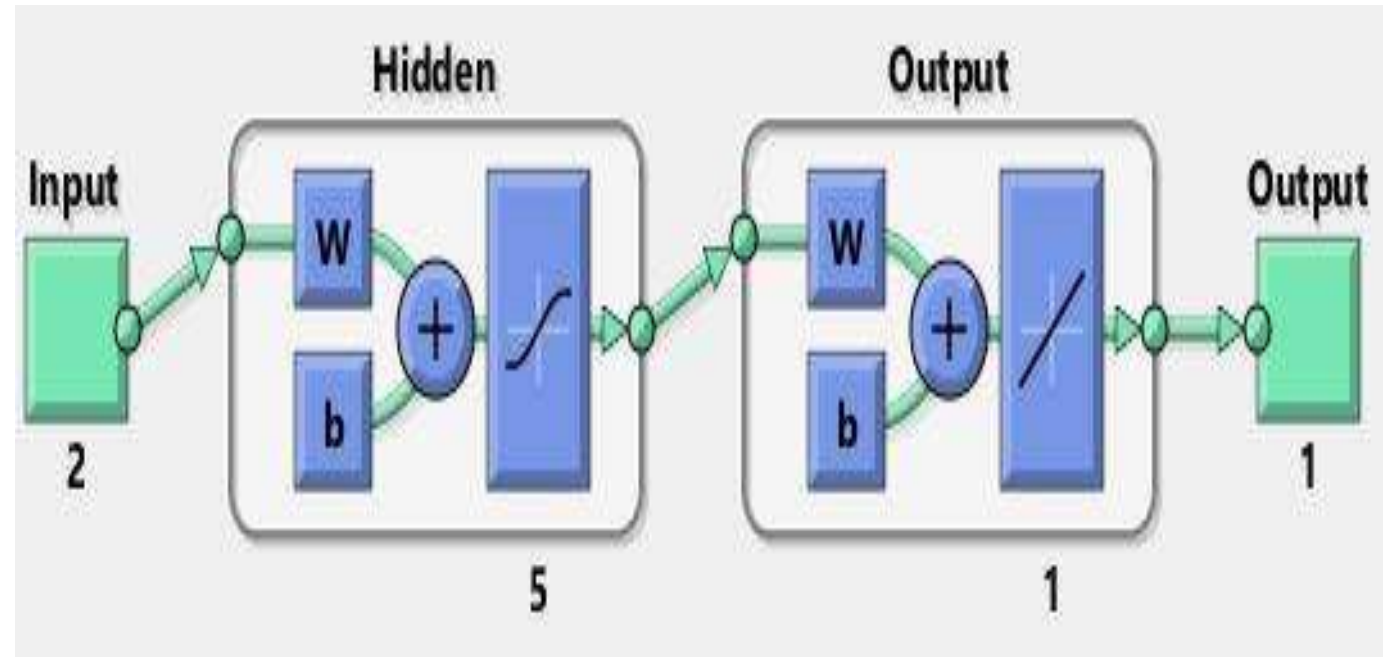

Fig. 2.3 Neural Network Model

The inputs to neural network are temperature and irradiance and the output is the voltage at the maximum power point. In hidden layer of the basics function is weighted linear sum and activation function and tansig. For output layer basis function is linear weighted sum whereas activation function is Linear. The algorithm used is LevenbergMarquardt. Among 16 data sets 10 data sets are used for training, 4 data sets for validating and 2 for testing. The MATLAB program for developing neural network is,

$\mathrm{x} 1=[201000 ; 251000 ; 301000 ; 351000 ; 401000 ; 451000 ; 50$

1000;25 200;25 300;25 400;25 500;25 600;25 700;25 800;25

900;25 1000];

$\mathrm{x}=\mathrm{x} 1^{\prime}$;

$\mathrm{t} 1=[296.8 ; 290 ; 283.2 ; 276.6 ; 270 ; 263.4 ; 256.8 ; 287.5 ; 291.1 ; 292$

$.6 ; 293.3 ; 293.3 ; 292.6 ; 291.9 ; 289.6 ; 290]$;

$\mathrm{t}=\mathrm{t} 1^{\prime}$;

net $=$ feedforwardnet $(5)$;

net $=\operatorname{train}($ net $, \mathrm{x}, \mathrm{t})$;

$\operatorname{view}($ net)

$\mathrm{y}=\operatorname{net}(\mathrm{x})$;

perf $=$ perform $($ net $, \mathrm{y}, \mathrm{t})$

DOI Number: https://doi.org/10.30780/IJTRS.V04.I06.003

pg. 22

www.ijtrs.com

WWw.ijtrs.org

Paper Id: IJTRS-V4-I5-029

Volume IV Issue VI, June 2019 


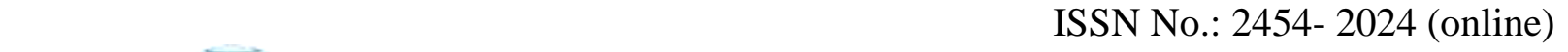

$7 \mathrm{R} \rightleftharpoons$ International Journal of Technical Research \& Science

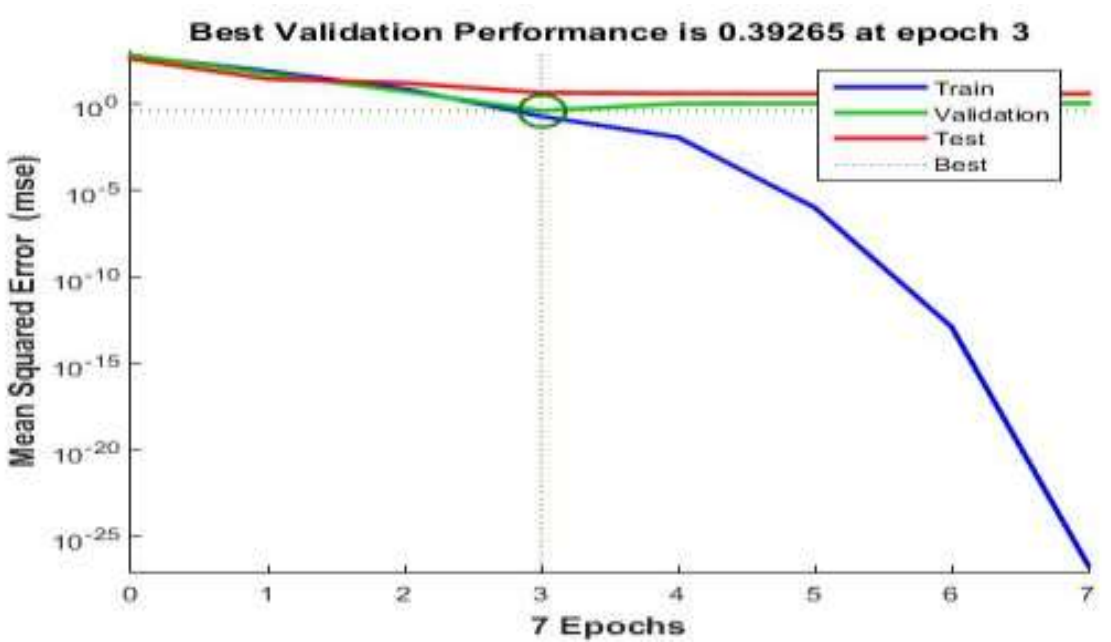

Fig. 2.4 Performance of Neural network

This function is 'gensim' is used to produced the Simulink block from above program. Now, so generated output from neural network is compared with the PV cells output voltage and error is passed through PI controller. The output of the PI controller is used as reference signal for generating necessary gating pulses for IGBT.
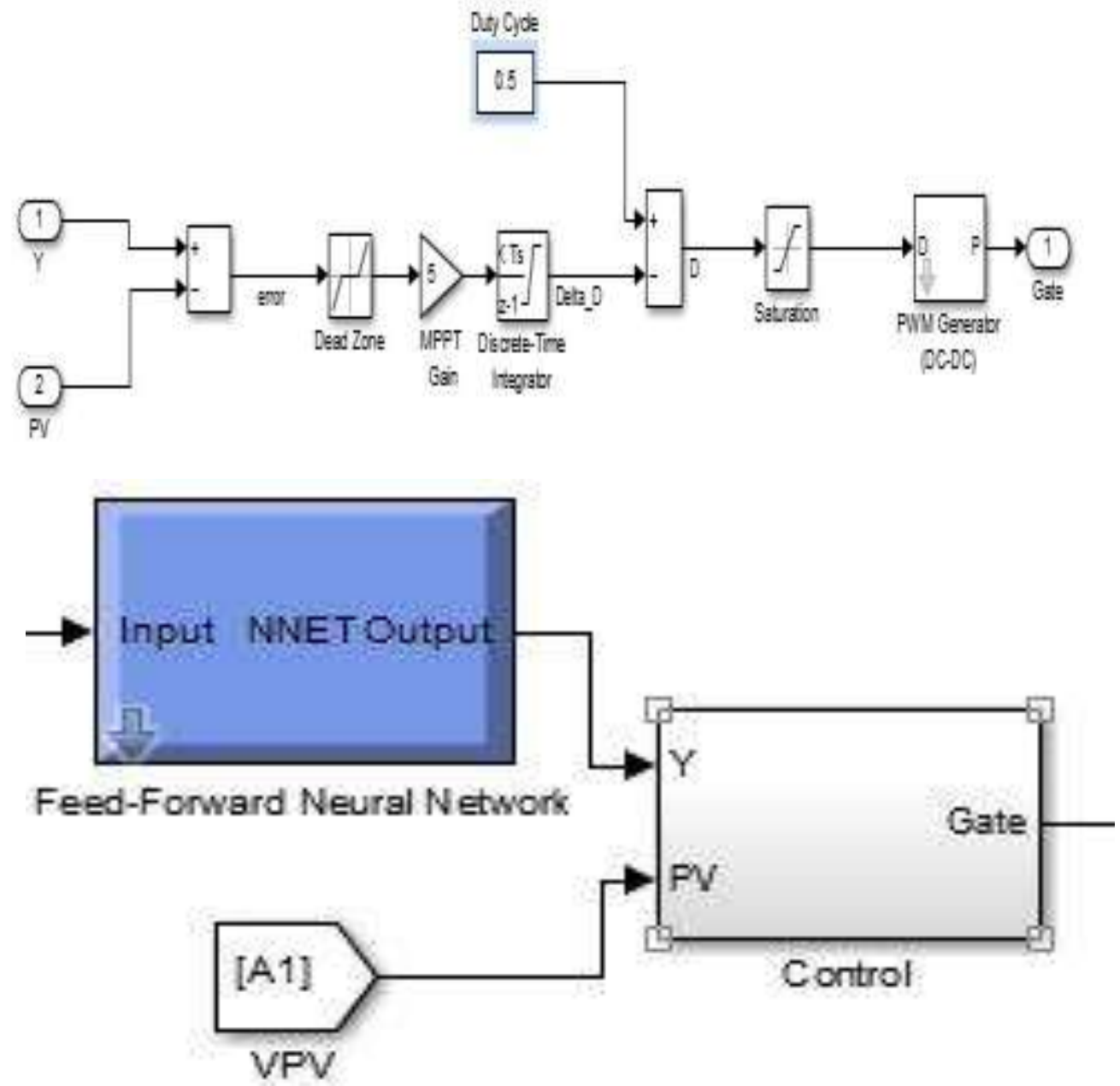

Fig. 2.5 MATLAB/Simulink Block Diagram for ANN Based Controller Block

\subsection{Boost Converter}

A boost converter is similar to step up chopper i.e. used to step up the input voltage level. The circuit diagram for the Boost regulator using IGBT is as below,

DOI Number: https://doi.org/10.30780/IJTRS.V04.I06.003

pg. 23

WWw.ijtrs.com

wWw.ijtrs.org

Paper Id: IJTRS-V4-I5-029

Volume IV Issue VI, June 2019 


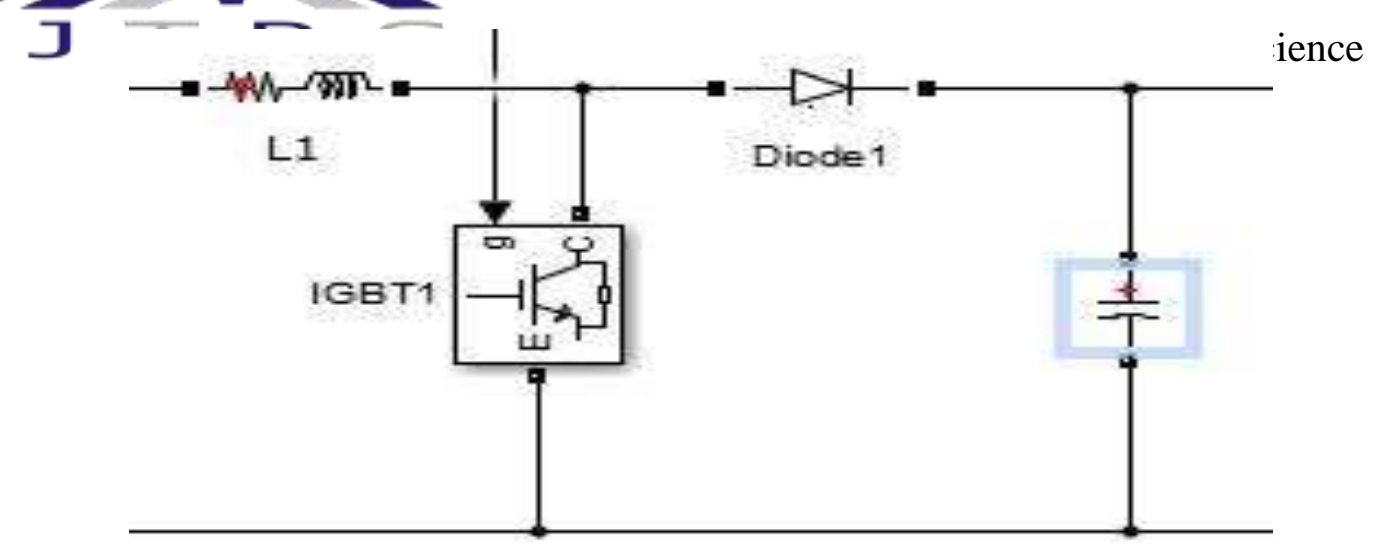

Fig. 2.6 Boost Converter

When the IGBT (Insulated gate bipolar transistor) is on current flows through inductor and IGBT and energy gets stored in the inductor. Now when IGBT is turned off then energy previously stored in the inductor is released through capacitor and load. The amount by which the output voltage gets boosted up depends upon the duty ratio.

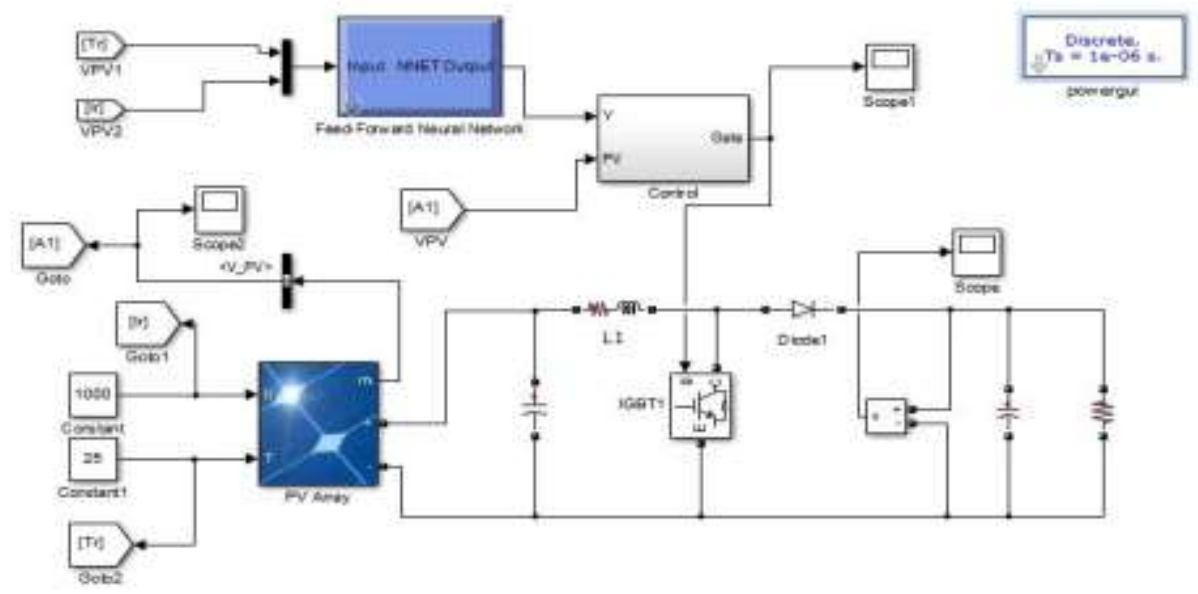

Fig. 2.7 MATLAB/Simulink Block Diagram of Proposed System

The model is simulated for $1 \mathrm{sec}$. Case I: Without using ANN. In this approach ANN block is replaced by another MPPT controller based on Incremental Conductance method.

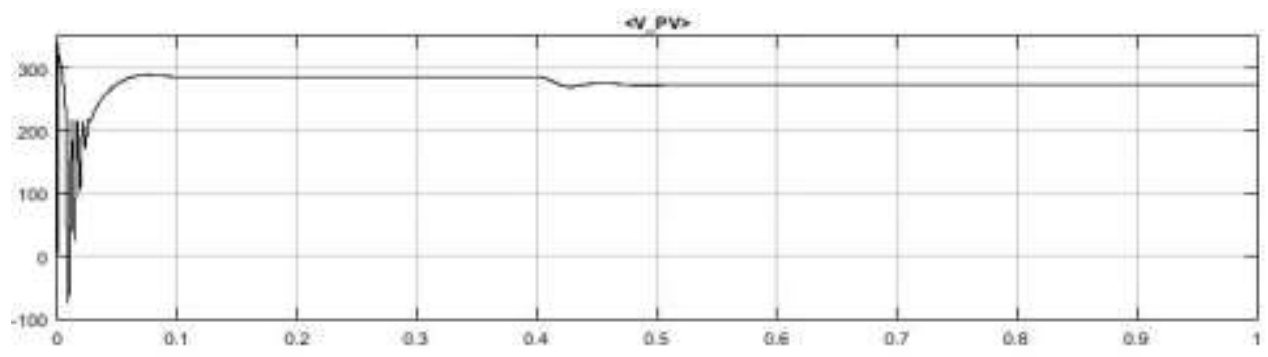

Fig. 2.8 PV Output Voltage

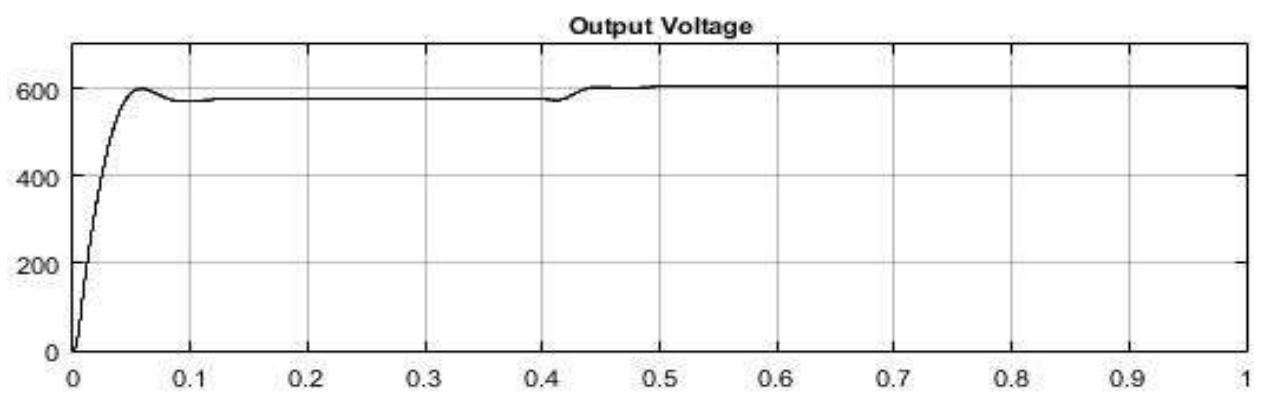

Fig. 2.9 DC Output Voltage After Boost Converter

DOI Number: https://doi.org/10.30780/IJTRS.V04.I06.003

pg. 24

www.ijtrs.com

Www.ijtrs.org

Paper Id: IJTRS-V4-I5-029

Volume IV Issue VI, June 2019 


\section{J T $R$ S International Journal of Technical Research \& Science}

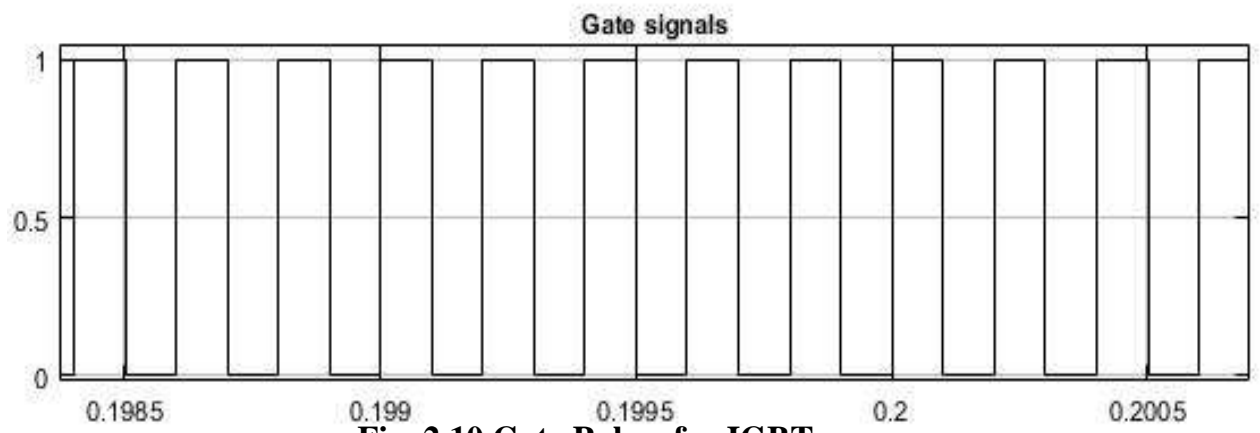

Case II: Using ANN based MPPT

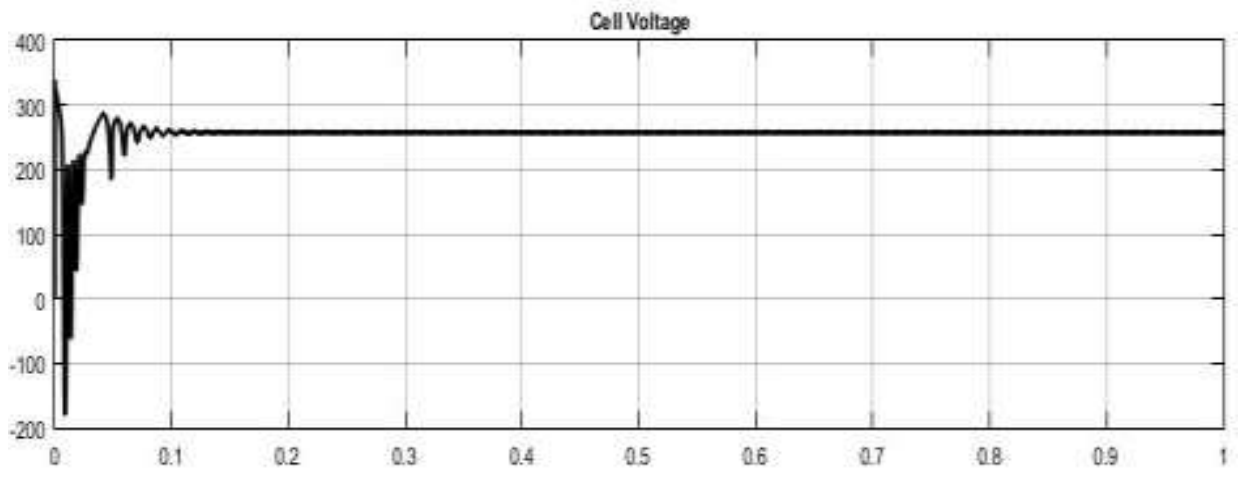

Fig. 2.11 PV Output Voltage

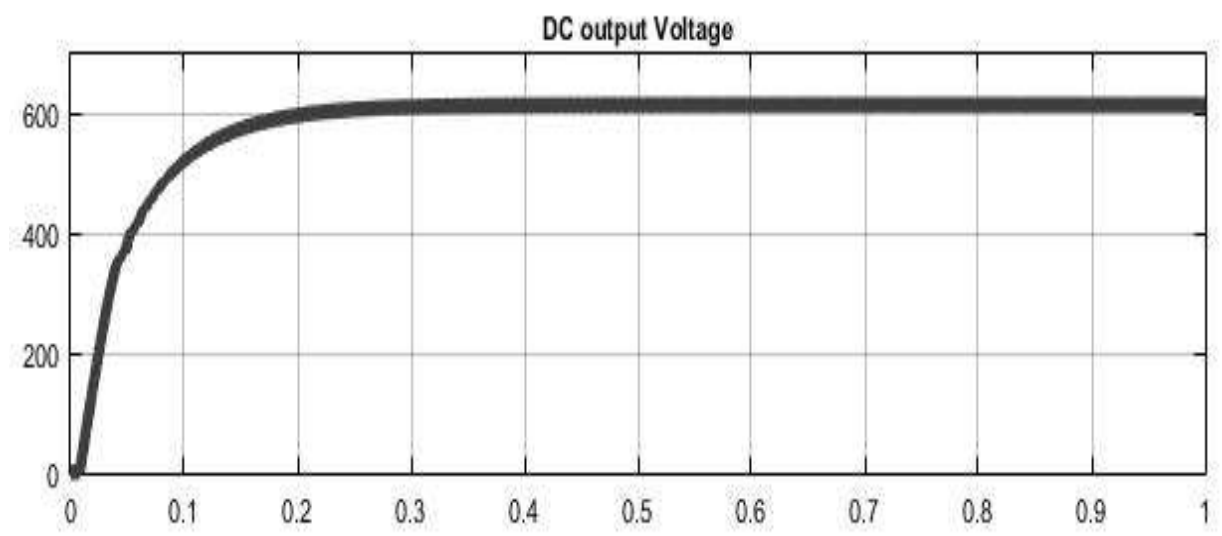

Fig. 2.12 DC Output Voltage After Boost Converter

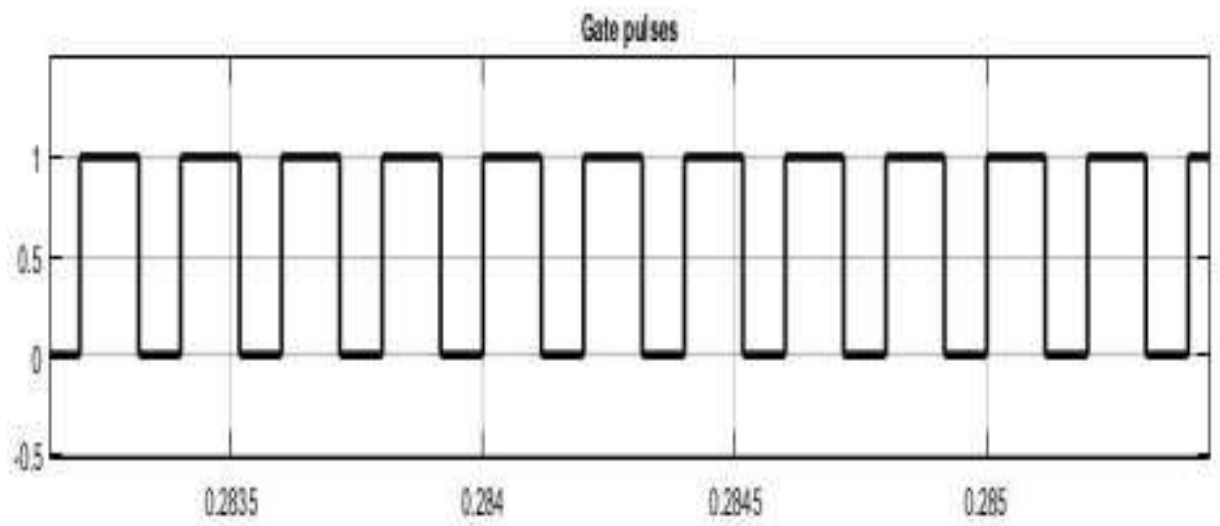

Fig. 2.13 Gate Pulses for IGBT

DOI Number: https://doi.org/10.30780/IJTRS.V04.I06.003

pg. 25

www.ijtrs.com

Www.ijtrs.org

Paper Id: IJTRS-V4-I5-029

Volume IV Issue VI, June 2019 @2017, IJTRS All Right Reserved 


\section{CONCLUSIONS}

The output voltage using the ANN based on the MPPT controller is more smooth and it contained lesser oscillations. The controller is more robust and fast in nature. In this paper only 16 number of data sets are used but if large number of data sets is used to train the network then still more robust and accurate controller can be made.

\section{REFERENCES}

[1] https://en.wikipedia.org/wiki/Maximum_power_point_tracking.

[2] Mathur, D., "Maximum Power Point Tracking with Artificial Neural Network" International Journal of Emerging Science and Engineering (IJESE) ISSN: 2319-6378, Volume-2, Issue-3, January 2014

[3] Atallah, A.H., Abdelaziz, A.Y., and Jumaa, R.S., "Implementation of perturb and observe mppt of pv system with direct control method using buck and buck boost converter" An international Journal (EEIEJ), Vol. 1, No. 1, February 2014.

[4] https://en.wikipedia.org/wiki/Artificial_neural_network. 